Research and theory related to a dynamic systems perspective on emotion argue that emotions are relational, not individual; selforganizing systems, not generated outputs; and processes of change, not states.

\title{
Communication of Smiling and Laughter in Mother-Infant Play: Research on Emotion from a Dynamic Systems Perspective
}

Alan Fogel; K. Laurie Dickson, Hui-chin Hsu, Daniel Messinger, G. Christina Nelson-Goens, Evangeline Nwokah

In this chapter we present a summary of our recent work examining emotional development in infancy from a dynamic systems perspective. Our goal is to describe the studies that have evolved from our research group and to explain how these studies have been informed by dynamic systems thinking. Reviews of our dynamic systems approach to emotional development can be found in the following works: Dickson, Fogel, and Messinger (forthcoming); Fogel and others (1992); Fogel, Nwokah, and Karns (1991); Fogel and Thelen (1987); and Messinger, Fogel, and Dickson (1997). Additional theoretical discussions of dynamic systems approaches applied to emotion can be found in Camras (1992), Haviland and Kahlbaugh (1993), Lewis (1993, 1995), and Wolff (1987)

We open this chapter with a theoretical overview, followed by a report on our work on the development of emotions related to the expressions of smiling and laughter during the first three years of life in the context of parentinfant play. Smiling is examined in the following social contexts: during face-to-face mother-infant communication (from one to six months), during

This work was supported by grants to Alan Fogel from the National Institute of Health (RO1 HD21036) the National Science Foundation (BNS9006756), and the National Institute of Mental Health (RO1 MH48680). 
normal and experimentally perturbed peekaboo and tickle games (at six and twelve months), and in play activities with mothers and fathers in the home (at twelve months). Finally, we report our studies of the social contextual aspects of the development of laughter in the first three years.

\section{The Dynamic Systems Perspective on Emotion}

We begin with a theoretical overview of the major features of a dynamic systems perspective on emotion. The features we emphasize are the following: (1) emotions are relational not individual; (2) empize are the following: (1) tems, not and (3) emotionses of change, not tures. We defer giving a concrete definition of emotion until after these feaEne been introduced.

Emotions Are Relational, Not Individual. How can it happen that emotional experiences are relational even though they are experienced by individuals? Our answer to this question, based on our dynamic systems perspective on emotion, is similar to functionalist theories of emotion in that both theories focus on emotional experiences as relational processes, as arising in the relationship between the individual and the object of emotion (Barrett, 1993; Barrett and Campos, 1987; Campos, Mumme, Kermoian, and Campos, 1994;
Frijda, 1986).

When emotional experience is relational, individuals do not perceive themselves as "having" an emotion, because individuals are not necessarily aware of themselves as creating or even as participating in the experience According to de Rivera (1992, p. 200), "emotions may be conceived as existing between people, as various sorts of attractions and repulsions ... which transform their bodies and perceptions." According to Frijda (1986. . 188) emotional experience "is glued as it were, to its object conca (1986, P. 188), apprehending that object's nature and significaject, coinciding entirely with experience is perception of experience is perception of horrible objects, insupportable people, oppressive
events."

This aspect of emotion is called nonreflective experience, that is, "awareness without awareness of itself, without some supervisor inspecting it" (Frijda, 1986, p. 188). In Frijda's functionalist theory of emotion, other people and objects are perceived as integral parts of an individual's (nonreflective) experience of emotion. The view of emotion as immediate, nonevaluative, direct experience is also shared by differential emotional theorists (Demos, 1992. Izard, 1991; Tomkins, 1962). "In differential-emotions theory (Demos, 1992; rience is defined as a quality of consciousness" (Izard, 1993, p. 633).

Emotional experiences are relational but they do not have to occur in the context of live interpersonal relationships. An individual can experience a relationship with inanimate and animate thing, wive can experience a relaobjects. Relationships can atso be remember with both natural and cultural be intrapsychic as well as interpersonal and in for an emotional experience is that there is a meaningful connection that moves the individual, one that establishes the significance or function of the emotional object for the individual in relation to that object (Hinde, 1985; Malatesta-Magai and Izard, 1991).

A contrasting aspect of emotional experience, reflective experience, occurs whenever individuals distinguish themselves from others, whenever individuals conceptualize relationships into independent constituents (Frijda, 1986). Reflective experience breaks down the relationship into its component parts and introduces a self and an object into consciousness, changing the experience from direct to analytical (Campos, Mumme, Kermoian, and Campos, 1994).

Emotional experience has both nonreflective and reflective aspects. Reflective appraisals and evaluations can become part of the experience of emotion as individuals evaluate their own history of experience and appraisal (Frijda, 1986). In addition, people can become (nonreflectively) emotional about their evaluations of themselves or others: I can be (nonreflectively) unhappy if decide (reflectively) that I reacted negatively to another person; I can be (nonreflectively) afraid if I evaluate (reflectively) another's motives as threatening regardless of whether they were so intended.

This alternation between a relational (nonreflective) and an analytic (reflective) mode has been conceptualized by Lewis (1995), for example, as the cycling between cognition and emotion. According to Izard, "emotion experience proper does not include cognition; however, emotion experience is cue-producing, and, as such, it nomally recruits the cognitive system" (Izard, 1993, p. 633). From our dynamic systems perspective, there is not a discrete and defined boundary between the relational and analytical aspects of emotion, nor between cognition and emotion. Rather, these two features of experience share a figure-ground relationship that varies with the situation. Sometimes we are more distant, analytic, observational, and controlled, as the figure against the ground of nonreflective experiential flow. Other times we are more caught up in the direct flow of the relationship, which becomes the figure against the ground of our appraisal of the experience.

Because there are many types of relationships, there can be many subtle varieties of emotional experience. Different emotional experiences reflect varieties of relationships with the environment as well as the particular form of action and physiological changes that occur in that relationship. These relational experiences cohere into recognizable emotions and families of emotion (Barrett, 1993; Barrett and Campos, 1987; Campos, Mumme, Kermoian, and Campos, 1994; Fogel and others, 1992; Frijda, 1986).

Emotions Are Self-Organizing Systems, Not Generated Outputs. Emotions are processes that have experiential, sociocultural, and physiological aspects. We use the term constituent to refer to any classification of the components of an emotion process. Constituents are conceptualizations; they are abstractions from lived emotional experience. Constituents include the form of action employed (including the facial expressions, postures, and movements), appraisals and thoughts, ongoing and prior emotions, autonomic processes, central nervous system processes, and relevant features of objects 
and people (Barrett, 1993; Ekman, 1994; Fogel and others, 1992; Izard, 1991; Izard and Malatesta, 1987). According to Izard (1993, p. 633), for example, "emotion has three levels or aspects-neural, expressive, and experientialand the term 'emotion' refers to all three components operating as an integral
system."

To explain the basis for coherent patterns of relationships between con stituents, we use the dynamic systems concept of self-organization. Selforganization occurs as constituents act together to constrain the possible actions of other constituents so that the complex system organizes into stable relational patterns called attractors (Fogel and Thelen, 1987; Kugler Kelso, and Turvey, 1982; Prigogine and Stengers, 1984). The relational artrac tors involve the brain and central nervous system, but there is no reason to assume that the brain is the executive or controller of an emotional process: it is only one constituent of the self-organizing process (Fogel and others, 1992 Messinger and others, 1997; Mischel, Camras, and Sullivan, 1992)

In this view, constituents are not entities with immutable characteristics. Constituents change as they enter into relational processes, altering their independent identities (Barrett, 1993; Fogel and others, 1992). The alteration occurs as changes in the form and function of the constituents. The "memory" of the system is to be found not in learned associations or genetic codes but in the historically preserved changes of system constituents as they become selforganized into a relationship.

For example, the brain changes in both real and developmental time with respect to interactive changes in other people, body movements, and other emotion constituents. Ontogenetically the brain loses much of its initial openness to input as its function becomes increasingly tailored to the specific experiences of the individual. Rather than thinking of neural programs as the cause or organizer of ontogenetic changes, they can be explained as stable attractors that are the ontogenetic result of a self-organizing process (Fogel and others, 1992; Messinger, Fogel, and Dickson, 1997). Phylogenesis provides the raw materials for particular manifestations of emotion, but these materials are processes rather than products, coregulations rather than codes, synergies rather than structures (Prigogine and Stengers, 1984).

In addition, relational attractors that emerge through self-organization are dynamically stable. This means that although they are processes that occur in time, they preserve their integrity across a wide variety of conditions. The concept of stability replaces the concept of memory, habit, and association in traditional theories of psychology (see Fogel, 1993, and Thelen and Smith, 1994 for further elaboration). The stability of the system can often be altered under specific kinds of perturbations that force the system to change by making a phase transition from one attractor to another (Kugler, Kelso, and Turvey, 1982; Prigogine and Stengers, 1984; Thelen and Smith, 1994). The relational attractors are encoded neither in the brain nor in the environment. Rather time similar conditions recur, the attractor is reconstituted dynamically, that is, by self-organization. This is because the constituents, having changed in order to establish those particular forms of relationship, are predisposed in the future to recreate those same relationships in similar situations.

Finally, we do not have to assume that there is some form of executive control over the formation of attractors in self-organizing systems. The brain, although of crucial importance in any emotional process, is only one constituent in the system. Research in emotional development shows that both behavior and development often appear to be led or regulated by one or another constituent of the system (Fogel and Thelen, 1987; Fogel and others, 1992). While a neural constituent may lead the self-organization of an emotion process at one moment, a motor or social constituent may lead at another time. Dynamic systems perspectives recognize that there are emotion constituents not only in the brain but also in the motor system, the social system, and the physical and cultural environment: all of these are essential to the creation and maintenance of relationships via self-organization (Fogel and Thelen, 1987).

These features of self-organization bear upon the hypothesized existence of a small number of discretely different emotions, as proposed by differential emotions theory (Izard and Malatesta, 1987; Ekman, 1994). As we have argued elsewhere, on the basis of our review of studies of young infants, there are insufficient data on emotional action to conclude that there are a relatively small number of pan-cultural "basic" emotions, regardless of the theoretical position. There are virtually no carefully done behavioral ethologies on which to base inferences about early emotional development in young infants of any culture (Fogel and others, 1992).

If, however, a relatively small number of basic emotions can be shown to exist pan-culturally, we would differ from the differential emotion theory with respect to the explanation for such emotions. In our view, these hypothetical basic emotions would be neither innate nor acquired, nor would they be considered hardwired structures of the brain or body. Differential emotions would be conceptualized as stable self-organized processes that tend to recur under particular organismic and functional conditions in a sociocultural environment (Barrett, 1993; Fogel and others, 1992; see also Haviland and Kahlbaugh, 1993; Shweder, 1994; Stein, Trabasso, and Liwag, 1993):

The concept of self-organization has several advantages. First, we can explain why stable and highly regular patterns recur using the concept of dynamic stability of a relational attractor. This requires data on the processes of self-organization in real time rather than a discrete coding of a single facial expression or the labeling of a single emotion removed from its sociocultural and temporal context.

Second, we can also explain the obvious variability in emotion and expression of individuals, groups, and cultures by something more than leamed associations. We hypothesize that variability arises because of subtle alterations in the constituents, variations that produce perturbations in the dynamics of self-organization that may predispose the system to make transitions to other attractors or to form entirely new attractors. With ime-based data we can potentially explain why some emotions are very stable and others are more labile and variable. 
Finally, as shown in the next section, we can explain how change, in real time and developmental time, occurs in emotional processes. Again, research needs to focus on processes of change within relationships (between the individual and a social partner, object, or situation). These relationships can be followed over time, ontogenetically, in order to trace the developmental history of stable emotional attractors, some of which can be interpreted as temperamental or personality configurations (Fogel and others, 1992; Haviland and Goldston, 1992; Lewis, 1995; Magai and Hunziker, 1993).

Emotions Are Processes of Change, Not States. One of the most important contributions of dynamic systems thinking to psychology is that change is conceptualized as an integral part of the everyday action of the system. The psychological system is never thought of as hardwired. In psychological systems, regularities arise from the "soft" assembly of self-organization, and because this is dynamic there is always variability and change (Fogel and Thelen, 1987; Thelen and Smith, 1994).

From this perspective, emotional experience is not only relational; it is also the experience of being a participant in the creation of a relationship. Living systems, from cells to organisms, are sustained by creative processes. Creativity occurs whenever attractors emerge via self-organization-attractors that are more than the sum of the constituent parts (Fogel, 1993). Part of the emotional experience is the experience of the relationship coming together (Averill and Thomas-Knowles, 1991; Barrett, 1993; de Rivera, 1992; Fogel, 1993). Creativity does not mean that people can make up emotions anew each time they occur. Rather, creativity refers to the experience of being a participant in a living process that leaves some room for unplanned occurrences and individual flexibility within a system of constraints.

Thus, for example, we experience fear as a change in our relationship to something fearful, with respect to the action readiness for self-protection and the action of escape. Enjoyment is the experience of a change in one's appreciation for and possibly one's movement closer to an object, person, or situation to which the experience is related. Infants, for example, will smile and laugh when they are able to kick freely following the removal of their clothes, an appreciation of a change from one situation to another.

Finally, a major implication of thinking about emotion as the experience of change is that we can better understand the foundations of emotional development. The dynamic systems perspective assumes that when emotional constituents (such as facial expressions) develop, it is attributable to some change or alteration in the self-organizing process by which the constituents coordinate their mutual relationship. Development is conceptualized as a change in how a system's constituents influence one another to create a newly emergent set of relational attractors. This is contrasted with the traditional view of development as a change in the set of associations between immutable components or the appearance of new fixed structures. The resulting relational attractors are new self-organizations of the same mutually constraining constituentsalthough these constituents have changes in relation to one another-rather than the activation of new executive controls (Fogel and Thelen, 1987; Thelen and Smith, 1994).

As a result of repeated experiences of change, we become aware of increasingly subtle aspects of change, inchuding our own development over time. Our emotions develop not only with respect to awareness of relational processes but also with respect to our own role in the creation of those relational processes. Emotions, as they shift between reflective and nonreflective forms of experience, are significant in the perception of our own subjectivity, our self as a creative (or noncreative) participant in a relational process (Fogel, 1993, 1996; Frijda, 1986; Haviland and Kahlbaugh, 1993).

\section{Human Emotion in Everyday Activities}

In this section we move beyond a general description of the theoretical principles to discuss how they might apply to human emotional processes in everyday life. According to our theory, the systemic unit of emotional experience is neither the individual nor particular actions or expressions (constituents) but, instead, dynamically stable relational attractors. What are these relational attractors in human emotional processes? We propose that they are communication frames.

In social communication, frames are segments of co-action that have a coherent theme, that take place in a specific location, and that involve particular forms of co-orientation between participants. Examples of frames are greetings, topics of conversation, conflicts, or children's social games. The meaning of an action in a conflict, for example, is related to features of the conflict frame, including the history of conflicts with a particular partner, the cultural rules for argumentation, and the relation of the particular actions to those just prior and those next likely to occur (Bateson, 1955; Fogel, 1993; Goffman, 1974; Kendon, 1985). In nonsocial communication, frames are the forms of everyday engagement with cultural tools and artifacts, and with the natural environment.

Frames are coherent patterns, attractors, that result from self-organizing processes. Frames are the locus of making actions meaningful, and they provide the stable background of regularity against which novelty (creativity) is perceived to emerge. Because they have a direction of flow across time, frames make action inherently oriented toward something that is about to occur. If we place our prior discussion of emotion into the context of frames, then emotional experience is the psychological meaning of participation in a relational frame.

The specific type of emotional process is closely tied to qualitative differences in the communication process within the frame. Positive emotions are more likely to occur when the frame involves mutual participation, when partners are each creatively elaborating the theme of the frame, and when there is a balance in their contributions to the frame. Negative emotion is more likely to occur when frames are coercive, when one partner exerts undue control that leads to withdrawal or resistance of the others.(Fogel, Walker, and Dodd, 1997). The quality of emotion also depends on whether frames are part; of 
ongoing relationships, and then on whether they are newly emergent or have a history within the relationship (Fogel and Lyra, forthcoming). In the research reviewed in this chapter we show how different types of positive emotion are related to specific features of the communication process during parent-infant interaction.

The concept of frame is similar to that of narrative, used when discussing linguistic communication. Narratives provide the framework by which each of their constituent actions and events share some meaningful relationship; they have a stable theme that emerges from the self-organization of the constiments; and they have an orientational direction of flow over time that motivates the movements of the actors, actions, and events (Hermans and Kempen, 1993; Haviland and Kahlbaugh, 1993; Jones, 1990; Ricoeur, 1983)

A number of emotion scholars have pointed to narrative themes as providing the minimal systemic unit of emotional experience. Tomkins (1962, 1978), for example, suggested that emotions arise dynamically with respect to the direction of changing contours of arousal activation that are embedded within narrative-like scripts and scenes within scripts, where scene and script are taken in the dramatic sense. Demos (1982) has described emotion processes. that are embedded in scripts of mother-infant play and has followed stability and change of emotion scripts within dyads. For Stern $(1985,1995)$, emotions are related to contours of activation with respect to changing dymamics in the creation of narrative-like action structures, called protonarrative envelopes, particularly those that occur in communication with others. For Ginsburg (1985), emotions arise with respect to directional sequences along situated lines of action in a context. Frijda (1986) suggests that emotions emerge in relationships with respect to the dynamic negotiation of individuals' concerns (thematic orientations of the individual), which direct the individual toward (thematic onentarelationship. Sarbin (1986) argues that emotions have the form. of a narrative because people generally describe and interpret their emotional experiences with respect to stories having a dramatic tension, rather thional experiences emotions in terms of simple stimuli and responses.

Emotions, therefore, are integral to the frame in which they occur. A dynamic systems perspective suggests that the whole frame, not any single action or event, should be the focus of research on emotion. In the next section, we review our own research with respect to these theoretical principles.

\section{Summary of Research Findings}

Development of Positive Emotion During Face-to-Face Play in the First Six Months. By three months of age, infants are capable of displaying a wide range of emotional expressions during face-to-face play with their mothers. Like other scholars (Barrett and Campos, 1987; Izard and Malatesta, 1987; Sroufe, 1979), we believe that these expressions are related to emotional experience. However, we do not believe that each expression has discrete meaning. From a dynamic systems perspective, different relational and temporal sequences could contribute to different meanings of anatomically identical smiles, and these different sequences could further amplify the differences in meaning between anatomically different smiles.

When and how do anatomically different types of smiles emerge developmentally during the face-to-face play frame between mothers and infants? Because we were interested in the process of developmental change, thirteen mothers and infants were videotaped playing together weekly when these full-term, normally developing infants were between one month and six months of age. Mothers were asked to hold their babies on their laps and play with them as they did at home. The images of mother and baby were captured with three video cameras that were synchronized into a split-screen display. To document interactive process, we separately coded facial actions that constitute different types of smiles, as well as other social actions such as infant gazing at mother and mother smiling. Facial actions were coded using the Facial Action Coding System (FACS) (Ekman and Friesen, 1978) as adapted for infants (Oster and Rosenstein, forthcoming). FACS-certified graduate students coded smiles, or lip comer raises (AU12), and cheek raises (AU6) caused by the contraction of the orbicularis oculi muscle. A third category, the degree of mouth openness (AU26c-AU27), was coded by undergraduate assistants trained by the FACS coders. In the Duchenne smile, both the lip corners (AU12) and the cheeks (AU6) are raised (Ekman and Friesen, 1978). In the play smile, the lip comers are raised and the mouth is opened into a jaw drop (AU26c-AU27). Finally, basic smiles involve neither cheek raising nor mouth opening.

When compared to smiles without orbicularis oculi contraction (nonDuchenne smiles), Duchenne smiles are associated with self-reported pleasure in adults (Ekman, Davidson, and Friesen, 1990; Fox and Davidson, 1988; Messinger, 1994). Fox and Davidson (1988) found that ten-month-old infants tended to Duchenne smile in response to their mothers who were smiling as they entered a room. Our group data also indicate that infants under six months tended to Duchenne smile when mother was smiling. Duchenne smiles were also prolonged when the infant was gazing at mother (Messinger, 1994).

These results suggest that under six months of age, infant Duchenne smiling is related to frames of visual mutuality, of eye contact and/or mutual smiling. Duchenne smiling is a salient constituent of an experience of positive, visually mediated connectedness between the infant and mother. The same interpretation may also be helpful for understanding evidence on Ducherne smiling in adults. Ekman, Davidson, and Friesen (1990) found that adults did more Duchenne smiling than non-Duchenne smiling in response to pleasan stimuli, such as films of animals playing. Adult Duchenne smiling may arise because adults perceive puppies and gorillas (example from Ekman and colleagues' 1990 data) enjoying themselves during play and imagine themselves participating in that perceived enjoyment. 
This does not mean that Duchenne smiles are the only true smiles of positive emotion and other smiles are not. Different types of smiles alternate with one another during positive engagement. In the context of the faceto-face frame over time, for example, non-Duchenne smiles change to Duchenne smiles as infants contract orbicularis oculi (raising their cheeks), and Duchenne smiles become non-Duchenne smiles as this muscle is relaxed. In our data, approximately one-half of Duchenne smiles were immediately preceded by non-Duchenne smiles, and approximately one quarter of non-Duchenne smiles were immediately preceded by Duchenne smiles, all within the same face-to-face play frame (Messinger, 1994). In earlier work we found that during face-to-face play frames gazing at mother and infant smiling were temporally linked, and that the infants tended to cycle between this state and gazing away without smiling (Kaye and Fogel, 1980). Thus the temporal patterns of facial actions within a frame suggest a neglected element of what infants and adults experience as, they interact. One hypothesis is that the infants' and mothers' experience of this sequential patterning becomes a stable relational attractor. We believe that this sequential pattern involves changing action orientations toward and away from continued mutual engagement-as evidenced in gazing at mother and smiling and then gazing away and not smiling - as well as cycling between Duchenne and non-Duchenne smiles during these periods of smiling. This sequential patterning achieves dynamic stability because, in the context of the relational frame, the invocation of any constituent (that is, gazing at mother or an infant smile) may lead to the dynamic self-organization of the relational pattern. The emotion, for the infant and the mother, is the experience of the occurrence of a particular type of coherent relational process, and also the experience of creatively increasing the chances that the experience will reliably recur.

Developmental change occurs when this stable relational pattern is disrupted and the same set of constituents reorganizes into a different communicative frame accompanied by different emotional experiences. After about four months of age, infants no longer look for long periods at their mother's face accompanied by extended smiling. No amount of maternal gazing, smiling, or postural manipulation of the infant can return the system to the former stable frame. A new stable frame emerges in which attention is directed jointly toward objects. Thus, in order to understand emotion we need to study the participatory process: how individuals orient to each other through mutually coregulated activities, create different forms of relational emotions, and reaffirm (or fail to) their mutual commitment and attachment.

In other research on the first six months and later we have found that multiple types of enjoyment experiences are associated with dialectically patterned relational frames. For example, the next section introduces the openmouthed play smile, which began during the first six months. Through its emphasis on multiple forms of positive experience and facial expressions, on sequences of interactive patterns, and on the relational stability of generalized patterns of interaction, a dynamic systems perspective has substantially expanded our appreciation of the sophistication of the emotional life of very young infants.

Positive Emotion in Everyday Activities at Twelve Months. Dickson, Walker, and Fogel (forthcoming) explored the communicative process between parents and their infants by examining infant smiles during different types of parent-infant play. The subjects were thirty-six Caucasian families with seventeen female and nineteen male twelve-month-old infants. Each parent-infant dyad was videotaped playing at their home for ten minutes. The videotaped sessions were coded continuously for smile type (basic, play/duplay, and Duchenne smiles) and play frame (object play, physical play, vocal play, and book reading). We found in this study that relatively few play smiles occurred. Rather, most smiles involving a jaw drop also contained a cheek raise. We refer to these as duplay smiles.

Log-linear analysis and descriptive narrative analysis revealed that different types of smiles occurred during different types of play frames. Duplay smiles occurred during physical play and object play frames more often than expected by chance, while Duchenne smiles occurred more often during book reading frames. Our results on the occurrence of play/duplay smiling illustrate the dynamic systems approach.

Play/duplay smiles involve both lip corner retraction and mouth opening. Why should these two actions become self-organized, and what is the possible emotional significance of the emergent relational pattern? First, infants may open their mouths into play/duplay smiles in order to increase their air intake during a physically stimulating activity. In one example from a mother-infant physical play frame, the infant's jaw dropped into a duplay smile and a giggle erupted each time the mother shook his body. The infant's jaw dropped simultaneously as the infant was inhaling deeply, which may help explain the occurrence of play/duplay smiles during physical play. Second, there is evidence that tactile stimulation may help create play/duplay smiles. In one father-infant physical play frame, the infant's jaw dropped into a duplay smile as the father's face touched her stomach. She began to laugh as he tickled her stomach with his face in a side-to-side motion. Her jaw closed into a basic smile as the father withdrew his physical stimulation.

Tactile stimulation alone, however, does not cause play/duplay smiles in a linear manner An example from a mother-infant physical play frame help illustrate the dynamic nature of the emotion process. The mother and infant leaned toward each other with basic smiles on their faces as the mother lay on the floor. The infant's cheeks raised into a Duchenne smile as the mother made rumbling sounds. Then the infant's jaw dropped into a duplay smile as the mother shook her head against the infant's stomach. The infant's face changed to a neutral expression just as the mother raised her head away from the infant's stomach. The infant then looked at a toy that was beside her. The mother quickly buried her face in the infant's stomach as she had moments before, yet the infant did not smile. The mother attempted again to stimulate 
the infant's stomach though the infant's attention remained focused on the block that she was now holding.

Thus, although tactile stimulation is one important constituent in play/duplay smiling, it does not cause the smile. The relational pattern that self-organizes depends on the sequential cycling, the dialectic between the constituents involved in the relationship: between different types of smiling, between smiling and gazing, and between different orientations of the body with respect to the partner. Tactile stimulation is related to the play smile at the beginning of the example just presented; however, later during the same session the constituents make a transition into a different self-organized pattern in which tactile stimulation is not related to play smiling. Other components in the system, such as the infant's increased desire to engage with the block, overstimulation from the tactile component, the mother's facial expressions, temporal patterns, and so on, may have played a key role in the transition from one communicative process involving smiling to another that does not involve smiling.

The emotional experience related to play smiling is created through the dialectical activity between the constituents of parent and infant action, facial expression, and physiological processes. The experience of positive emotion during play smiling varies according to the dynamics of these dialectics within the whole play frame. Shaking, tickling, and nuzzling each have unique temporal and physical features that self-organize with the play smile and other activities to create different types of physical play frames, different relational dialectics, and therefore different emotional experiences. Although we cannot come up with specific names for each of these types of emotional experience, we can recognize that they have a dynamic stability that is entirely relational. We have discovered remarkably complex relational dialectics within these play frames that distinguish one emotional experience from another and that reveal variability between dyads in the forms and creativity of their emotional experience (Dickson, Fogel, and Messinger, forthcoming; Fogel, Walker, and Dodd, 1997).

The Dynamics of Positive Emotion During Peekaboo and Tickle Games. Thus far the results reported suggest that emotional experiences need to be interpreted with respect to relational frames. We have found that there is an emotional dynamic within frames, described earlier as dialectical alternations berween Duchenne and non-Duchenne smiles or between play/duplay and nonplay/duplay smiles; between smiling and gazing; and between these smiles and gazes and other frame constituents.

To confirm the theoretical proposition that emotional experiences are closely tied to the dynamics of relational frames, we developed a procedure for experimentally altering the dynamics of activity within two particularly common frames in mother-infant relationships: peekaboo and tickle games.

This laboratory study examines the impact of small perturbations to the flow of social games in mother-daughter dyads when infants were six or twelve months. Dyads were randomly assigned to a control or an experimental group.
The participants were 105 Caucasian mother-daughter dyads. The six-monthold control group ( $n=26)$ included twelve infants, while the six-month-old experimental group $(n=27)$ had sixteen. The twelve-month-old control group $(n=28)$ had fourteen infants, and the twelve-month-old experimental group ( $n=24)$ had twelve. Regardless of group assignment, mothers were instructed to play a peekaboo and tickle game with their daughters. The game order was counterbalanced across dyads. Control dyads played the games regularly for six trials. Each trial had a dialectical structure, a sequence of cover (setup) followed by uncover (climax) for peekaboo games, and anticipation (setup) followed by tickling (climax) for tickle games. In perturbation dyads, mothers were asked to change the action in the climax portion of the games, thus perturbing the dialectical balance between the setup and climax. Each perturbed game had two normal trials, followed by two perturbed trials, and the last two trials were played normally. In perturbed tickle trials, mothers set up the game, saying "I'm gonna get you" while moving their fingers toward the infant, but then only pretended to tickle their infants. In perturbed peekaboo trials, mothers altered the game by covering their faces; however, they did not uncover their faces when they said "peekaboo."

Ekman and Friesen's (1978) FACS was used by certified coders to identify three components of positive infant facial expressions that were described earlier: AU12, AU6, and AU26/AU27. Then the data were grouped into basic, play, Duchenne, and duplay smiles. Infant gaze was coded for "at mother's face." We present findings for the control and perturbation groups separately, reporting results that obtained statistical significance using repeated-measures ANOVA.

Control Group. In the control group dyads, across all games and trials, there was more basic smiling in setup compared to climax, and more complex smiling in the climax. In addition, all smiles were more likely to be accompanied by gaze at mother in the climax. The basic smile apparently was connected with anticipation and with establishing a communicative link between infants and mothers that allowed the games to proceed. These findings show that positive emotion is not a unitary phenomenon; instead, it varies dynamically with gaze and other actions as a function of the phase of the communicative process within frames.

Peekaboo and tickle games also differed in their contour over trials. Generally, during tickle games there were more smile and smile-gaze co-occurrences in the first two trials, followed by a rapid decline of smiling over trials However, peekaboo games began with high smile-gaze co-occurrence and, depending on the type of smile, either remained steady or increased over trials. This pattern held for basic, Duchenne, and play smiles coupled and not coupled with gazing at mother. The opposite was true for duplay smiles: they increased over trials for tickle but decreased for peekaboo.

There were marked differences between frames in contours of positive emotion over trials. These real-time dynamics, as predicted from our systems 
theory, provide a novel window on emotional processes. Once emotion is viewed as a holistic process of change over time, rather than as a discrete-point response to a stimulus, an innovative way to think about altering and enhancing emotions and their development is opened up.

Perturbation Group. In peekaboo and tickle games, different patterns emerged with regard to infants' smiling (AU 12). During peekaboo games, both six-month-olds and twelve-month-olds smiled less during the perturbed trials than during the nonperturbed trials. After perturbed trials, six-month-olds returned to the level of smiling seen in the first normal trials, while twelvemonth-olds did not return to the same level of smiling after the perturbation. During tickle games, six-month-olds' smiling dropped in the perturbed trials, while twelve-month-olds' smiling remained relatively stable across trials. Because six-month-olds showed a significant decrease in smiling during the perturbed trials and returned to initial levels of smiling after the perturbed trials, they appear more reactive to the tickle perturbation than twelve-montholds. Also of interest is that for both games, basic smiles remained relatively unchanged between perturbed and nonperturbed trials. This suggests that basic smiles may have a communication maintenance function during transition periods in the frame.

These results show that even subtle and brief perturbations disturb the overall amount of positive emotion and the contours of positive emotion across trials. The results also reveal that for all groups except twelve-month-olds during tickle games, the infants returned to prior levels of emotion in trials immediately following the perturbed trials. This means that our perturbation was successful at maintaining the dynamics of the frame while at the same time revealing the close linkages between communicative actions and emotional expression.

Further research using different types of perturbations will be important in revealing the relative stability of these frames. Also, the changing selforganization of the various emotion constituents should reveal how emotional experience relates to the dynamics of the frame. Emotional experience can be inferred, as we have suggested, not from a simple reading of a facial expression but from the dialectical patterning of all of the game constituents as they unfold over time.

\section{Laughter as a Social Process}

In this section we discuss our findings on laughter. Generally, the results provide conclusions similar to those of our smiling studies: that expressions of emotions are dynamically embedded within relational frames that make them meaningful, and that those frames are composed of dialectical relationships between laughter and other action constituents. The results reported here come primarily from our longitudinal weekly and biweekly observations of thirteen infant-mother dyads playing in a laboratory playroom over the first year of life, and from such observations of eleven of these dyads during the second year. Three additional observations of nine of the dyads were obtained at age three.
Laughter onset is typically dramatic and sudden, and involves vocalizations, actions, and physiological changes (Nwokah and others, 1993). According to our theoretical perspective, the sudden and dramatic transition to laughter by one or more partners is related to the dynamics of self-organization in the constituents of partner and contextual contributions to the relationship. This transition is often predictable but not precisely so, particularly because there are constant developmental changes in the constituents of laughter during the first three years.

According to our data, infants produce their first laugh in the context of infant-caregiver interaction at anywhere from ten to twenty-one weeks of age (Nwokah, Hsu, Dobrowolska, and Fogel, 1994). Early pseudolaughter is highly variable and may show some qualities of quasi-resonant vocalizations (Oller, 1986; Nathani and Stark, 1995) as a result of the limited respiratory and anatomical oral-motor constraints of the infant (Nwokah, Hsu, Dobrowolska, and Fogel, 1994). However, mothers are able to recognize, label, and comment on their infants' first laughs (Nwokah and Fogel, 1993). Once laughter emerges in the infant's vocal repertoire, it becomes a frequent part of the repetitive interactions between mother and infant, with many mothers producing five to twenty laughs and infants one to four laughs in a ten-minute face-toface play session. During the first two years we found a peak in the frequency of maternal laughter for each mother during the months between the onset of infant laughter at three to four months and six months of age, when infant crawling typically reduces the frequency of face-to-face interactions (Nwokah and Fogel, 1993; Nwokah, Hsu, Dobrowolska, and Fogel, 1994).

Much as we found different types of smiling, we found different forms of infant laughter, such as comment (one peak), chuckle (two peaks), rhythmi$\mathrm{cal}$ (several peaks), and squeal (high fundamental frequency), using acoustic analysis. Also, similar to our findings on the differential occurrence of different smile types within different play frames, we found that different forms of laughter are generally associated with different relational frames. Rhythmical laughs, for example, occur more frequently during mother-infant social play frames, while comment and chuckle laughs occur more frequently in object exploratory frames, both object play alone and joint object play (Nwokah, Hsu, Davies, and Fogel, 1991; Nwokah, Davies, Hsu, and Fogel, 1993).

By one year of age, infant and mother can anticipate that by dialectically alternating their tone of voice, facial expressions, and actions, they can build up to a laugh. Mothers pretend to be angry or stern and chase the toddler, who giggles. The toddler teases the mother by doing something potentially dangerous, like standing on top of the slide but constantly referencing the mother and modulating what she or he is doing while laughing at the mother's concern. Although mothers can encourage a sudden laugh or build-up to laughter in the infant by incongruity such as putting a toy on their own head, such factors as the timing, element of surprise, and attention of the infant are also important. What might change to laughter on one occasion may not do so on another. 
The consolidation of the mother-infant socioemotional relationship is also shown by developmental changes in the temporal characteristics of shared laughter. By the second year, the duration of maternal and infant laughter becomes more similar within dyads. In addition, the overlap of co-occurring laughs by the two partners becomes increasingly simultaneous, reflecting an increase in mutually coregulated frames and improvements in the infant's speed of vocal response (Nwokah, Hsu, Dobrowolska, and Fogel, 1994; Stern, 1985).

The dialectics of laughter and gaze also show developmental change. Before age six months, the infant nearly always looks at the mother's face while laughing during game playing. From six to twelve months, infants look at the mother's face before and during shared and infant-only laughter in differen social frames. If the activity is a social play frame, the infant looks away after laughing. However, after twelve months the infant is more likely to be looking away or at an object during laughter, both in game playing and during infant actions. Very brief gaze or glancing behavior at the mother by the infant is more likely to occur a few seconds after the child laughs, regardless of age.

Toward the end of the second year, a new developmental milestone is achieved: the onset of first words. The frequency of different facial expressions does not decrease at this time but continues to form the basic emotional foundation for the emergence of verbal communication (Bloom, 1993). Does laughter then exist as another vocal option? As infants develop perceptual and articulatory skills, they begin to combine laughter with the production of words or wordlike utterances (jargon) to create new possibilities for expressing intense affect while speaking (Nwokah and others, 1993). What develops from spoken words and vocal laughter is a combined signal containing some acoustic features of both speech and laughter.

Future studies may better determine how the pragmatic social function of laughter evolves in the context of a variety of daily frames and how individualized laughter styles emerge from the ongoing dynamics of the dyadic relationship: The results so far show that laughter, like smiling, as a constituent of positive emotional experience, varies in both form and dynamics. Laughter, like smiling, is a constituent in a large variety of relational patterns in the context of different frames. Finally, laughter, like smiling, is observed to alternate dialectically with other forms of action. This suggests that the quality of the emotional experience of laughter is not the same over all instances of the expression, and can be interpreted only with reference to the dynamics of the relational frame.

\section{Discussion}

In this chapter we have reviewed our research on emotional development in infancy from a dynamic systems perspective. We have proposed that emotional experiences are related to the self-organization of constituents in a relational frame. The relational frame occurs over some finite period, is created with respect to particular forms of action and arousal, and is composed of an alter- nating dialectic between different types of actions and physiological processes We have suggested that frames are a reasonable unit of emotional analysis, and that emotion-related actions can be interpreted with respect to the dynamic processes occurring in the frame, taken as a whole.

We discovered that many frames for positive emotion are dynamically stable over real time and developmental time and under the influence of certain types of perturbation. Developmental change can be understood with respect to the dynamics of transitions between frames and the emergence of novel frames in a relationship. In addition, this work also suggests that other frames may exist that are relatively unstable, and their role in emotional experience and its development requires further investigation. Furthermore, stability of frames may not always be adaptive if it is more functional for them to change (Lewis, 1995). Thus the concepts of our dynamic systems perspective have the potential to illuminate both normal and pathological emotional developmental processes

\section{References}

Averill, J. R., and Thomas-Knowles, C. "Emotional Creativity." In K. T. Strongman (ed.) International Review of Studies on Emotion, Vol. 1. New York: Wiley, 1991.

Barrett, K. C. "The Development of Nonverbal Communication of Emotion: A Functionalist Perspective." Journal of Nonverbal Behavior, 1993, 17, 145-169.

Barrett, K. C., and Campos, J. J. "Perspectives on Emotional Development II: A Functionalist Approach to Emotions" "In J. D. Osofsky (ed.). Handaook of Infant Development (2nd ed.) New York: Wiley, 1987.

Bateson, G. "The Message: 'This Is Play.' "In B. Schaffner (ed.), Group Processes, Vol. 2. Madison, N.J.: Madison Printing, 1955.

Bloom I "Developments in Expression: Affect and Words in the Single Word Period." In L. Bloom (ed.), The Transition from Infancy to Language: Acquiring the Power of Expression. New York: Cambridge University Press, 1993.

Campos, J. J., Mumme, D. L., Kermoian, R., and Campos, R. G. "A. Functionalist Perspective on the Nature of Emotion." In N. A. Fox (ed.), The Development of Emotion Regula tion: Biological and Behavioral Considerations. Monographs of the Society for Research in Child Development, 1994, 59 (2-3, serial no. 240), pp. 2-3.

Camras, L. A. "Expressive Development and Basic Emotions." Cognition and Emotion, 1992 6. 269-283.

de Rivera, J. "Emotional Climate: Social Structure and Emotional Dynamics." In K. I. Strongman (ed.), International Review of Studies on Emotion, Vol. 2. New York: Wiley, 1992.

Demos, E. V. "Facial Expressions of Infants and Toddlers: A Descriptive Analysis." In

T. Field and A. Fogel (eds.), Emotion and Early Interaction. Hillsdale, N.J.: Erlbaum, 1982.

Demos, E. V. "The Early Organization of the Psyche." In J. W. Barron, M. N. Eagle, and D. L. Wolitzky (eds.), Interface of Psychoanalysis and Psychology. Washington, D.C.: American Psychological Association, 1992

Dickson, K. L., Fogel, A., and Messinger, D. "The Development of Emotion from a Social Process View." In M. F. Mascolo and S. Griffen (eds.), What Develops in Emotional Development? New York: Plenum, forthcoming.

Dickson, K. L., Walker, H., and Fogel, A. "The Relationship Between Smile-Type and PlayType During Parent-Infant Play." Developmental Psychology, forthcoming. 
Ekman, P. "All Emotions Are Basic." In P. Ekman and R. J. Davidson (eds.), The Nature of Emotion: Fundamental Questions. New York: Oxford University Press, 1994

Ekman, P., Davidson, R. J., and Friesen, W. "The Duchenne Smile: Emotional Expression and Brain Physiology II." Journal of Personality and Social Psychology, 1990, 58

Ekman, P., and Friesen, W. V. Facial Action Coding System: A Technique for the Measurement of Facial Movement. Palo Alto, Calif.: Consulting Psychologists Press, 1978.

Fogel, A. Developing Through Relationships. Chicago: University of Chicago Press, 1993.

Fogel, A. "Relational Narratives of the Pre-Linguistic Self." In P. Rochat (ed.), The Self in Early Infancy: Theory and Research. New York: Elsevier, 1996.

Fogel, A., and Lyra, M. "Dynamics of Development in Relationships." In F. Masterpasqua and P. Perna (eds.), The Psychological Meaning of Chaos: Self-Organization in Human Development and Psychotherapy. Washington, D.C.: American Psychological Association, forthcoming.

Fogel, A., Nwokah, E., Dedo, J. Y., Messinger, D., Dickson, K. L., Matusov, E., and Holt, S. A. "Social Process Theory of Emotion: A Dynamic Systems Approach." Social Develop-
ment, 1992, 1, 123-142.

Fogel, A., Nwokah, E., and Karns, J. "Parent-Infant Games as Dynamic Social Systems." In K. B. MacDonald (ed.), Parents and Children Playing. Albany, N.Y.: State University of New

Fogel, A, and Thelen, E. "Development of Early Expressive and Communicative Action: Reinterpreting the Evidence from a Dynamic Systems Perspective." Developmental Psychology, 1987, 23, 747-761.

Fogel, A., Walker, H., and Dodd, D. "Beyond Individuals: A Relational-Historical Approach to Theory and Research on Communication." Unpublished manuscript, 1997.

Fox, N., and Davidson, R. J. "Patterns of Brain Electrical Activity During Facial Signs of Emotion in Ten Month Old Infants." Developmental Psychology, 1988, 24, 230-236.

Frijda, N. The Emotions. New York: Cambridge University Press, 1986.

Ginsburg, G. P. "The Analysis of Human Action: Current Status and Future Potential." In G. P. Ginsburg, M. L. Brenner, and M. von Cranach (eds.), Discovery Strategies in the Psychology of Action. London: Academic Press, 1985

Goffman, E. Frame Analysis: An Essay on the Organization of Experience. Cambridge, Mass.: Harvard University Press, 1974.

Haviland, J. M., and Goldston, R. B. "Emotion and Narratiye: The Agony and the Ecstasy." In K. T. Strongman (ed.), International Review of Studies on Emotion, Vol. 2. New York: Wiley, 1992

Haviland, J. M., and Kahlbaugh, P. "Emotion and Identity." In M. Lewis and J. M. Haviland. (eds.), Handbook of Emotions. New York: Guilford Press, 1993.

Hermans, H.J.M., and Kempen, H.J.G. The Dialogical Self: Meaning as Movement. Orlando, Fla.: Academic Press, 1993

Hinde, R. "Expression and Negotiation." In G. Zivin (ed.), The Development of Expressive Behavior. Orlando, Fla.: Acádemic Press, 1985.

Izard, C. E. The Psychology of Emotions. New York: Plenum, 1991.

Lzard, C. E. "Organizational and Motivational Functions of Discrete Emotions." In M. Lewis and J. M. Haviland (eds.), Handbook of Enotions. New York: Guilford Press, 1993.

Izard, C. E., and Malatesta, C. Z. "Perspectives on Emotional Development I: Differential Emotions Theory of Early Emotional Development." In J. Osofsky (ed.), Handbook of Infant Development. (2nd ed.) New York: Wiley, 1987.

Jones, D. The Matrix of Narrative: Family Systems and the Semiotics of Story. Hawthome, N.Y.: Mouton de Gruyter, 1990

Kaye, K., and Fogel, A. "The Temporal Structure of Face-to-Face Communication Between Mothers and Infants." Developmental Psychology, 1980, 16, 454-464

Kendon, A. "Behavioral Foundations for the Process of Frame Attunement in Face-to-Face Interaction." In G. P. Ginsburg, M. Brenner, and M. von Cranach (eds.), Discovery Strategies in the Psychology of Action. Orlando, Fla.: Academic Press, 1985.
Kugler, P. N., Kelso, J.A.S., and Turvey, M. T. "On Coordination and Control in Naturally Developing Systems." In J.A.S. Kelso and J. E. Clark, (eds.), The Development of Movement Coordination and Control. New York: Wiley, 1982.

Lewis, M. D. "Emotion-Cognition Interactions in Early Development." Cognition and Emotion, 1993, 7, 145-170.

eewis, M. D. "Cognition-Emotion Feedback and the Self-Organization of Developmental Paths." Human Development, 1995, 38, 71-102

Magai, C. and Hunziker, ]. "Tolstoy and the Riddle of Developmental Transformation: A Life-Span Analysis of the Role of Emotions in Personality Development." In M. Lewis and J. M. Haviland (eds.), Handbook of Emotions. New York: Guilford Press, 1993.

Malatesta-Magai, C., and Izard, C. "View I: The Perspective from Differential Emotions Theory." In K. T. Strongman (ed.), International Review of Studies on Emotion, Vol. 1. New York: Wiley, 1991.

Messinger, D. S. "The Development of Smiling: A Dynamic Systems Approach." Unpublished doctoral dissertation, Department of Psychology, University of Utah, 1994.

Messinger, D., Fogel, A., and Dickson, K. L. "A Dynamic Systems Approach to Infant Facial Action." In J. A. Russell and F. M. Dols (eds.), The Psychology of Facial Expression. New York: Cambridge University Press, 1997.

Mischel, G. F., Camras, L. A., and Sullivan, G. "Infant Interest Expressions as Coordinative Structures." Infant Behavior and Development, 1992, 15, 347-358.

Nathani, S., and Stark, R. "Infant Vocalizations in Home and Laboratory Settings." Paper presented at American Speech-Language-Hearing Association Annual Convention, Orlando, Fla., Dec. 1995

Nwokah, E., Davies, P., Hsu, H. and Fogel, A. "The Integration of Speech and Laughter in Vocal Communication." Paper presented at the American-Speech-Language-Hearing Association

Nwokah, E., Davies, P., Islam, A., Hsu, H, C., and Fogel, A. "Vocal Affect in Three-YearOlds: A Quantitative Acoustic Analysis of Child Laughter." Joumal of the Acoustical Society of America, 1993, 94, 3076-3090.

Nwokah, E., and Fogel, A. "Laughter in Mother-Infant Emotional Communication." Humor: International Journal of Humor Research, 1993, 6, 137-161.

Nwokah, E., Hsu, H., Davies, P., and Fogel, A. "Stability and Change in Infant Laughter." Paper presented at the biennial meeting of the Society for Research in Child Development, Seattle, Wash., Apr. 1991.

Nwokah, E., Hsu, H., Dobrowolska, O., and Fogel, A. "The Development of Laughter in Mother-Infant in Communication: Timing Parameters and Temporal Sequences." Infant Behavior and Development, 1994, 16, 23-25.

Oller, D. K. "Metaphonology and Infant Vocalizations." In B. Lindblom and R. Zetterstrom (eds.), Precursors of Early Speech. New York: Stockton Press, 1986.

Oster, H., and Rosenstein, D. Baby FACS: Analyzing Facial Movement in Infants. Palo Alto, Calif.: Consulting Psychologists Press, forthcoming.

Prigogine, I., and Stengers, I. Order Out of Chaos: Man's New Dialogue with Nature. New York Bantam Books, 1984

Ricoeur, P. Time and Narrative, Vol. I (K. Mcíaughlin and D. Pellauer, trans.). Chicago University of Chicago Press, 1983.

Sarbin, T. R. Narrative Psychology: The Storied Nature of Human Conduct. New York: Praeger, 1986.

Shweder, R. A. "You're Not Sick, You're Just in Love": Emotion as an Interpretive System." In P. Ekman and R. J. Davidson (eds.), The Nature of Emotion. New York: Oxford University Press, 1994.

Sroufe, A. "Socioemotional Development." In J. Osofsky (ed.), Handbook of Infant Development. New York: Wiley, 1979.

Stein, N. L., Trabasso, T., and Liwag, M. "The Representation and Organization of EmoStein, N. L., Trabasso, T., and Liwag, M. "The Representation and Organization of Emo-
tional Experience: Unfolding the Emotion Episode." In M. Lewis and J. M. Haviland (eds.), Handbook of Emotions. New York: Guilford Press, 1993. 
Stem, D. The Interpersonal World of the Infant. New York: Basic Books, 1985. Stern, D. The Motherhood Constellation. New York: Basic Books, 1995.

Thelen, E., and Smith, L. A Dynamic Systems Approach to the Development of Cognition and Action. Cambridge, Mass:: Massachusetts Institute of Technology Press, 1994. Tomkins, S. Affect, Imagery and Consciousness, Vol. 1. New York: Springer, 1962.

Tomkins, S. S. "Script Theory: Differential Magnification of Affects." In H. E. Howe, Jr., and R. A. Dunstbier (eds.), Nebraska Symposium on Motivation. Lincoln: University of Nebraska Press, 1978.

Wolff, P. H. Behavioral States and the Expressions of Emotion in Early Infancy. Chicago: University of Chicago Press, 1987.

ALAN FOGEL is professor in the Department of Psychology at the University of Utah.

K. LAURIE DICKSON is assistant professor in the Department of Psychology at Northern Arizona University.

HUI-CHIN HSU is a research associate in the Department of Psychology at the University of Utah.

DANIEL MESSINGER is assistant professor in the Departments of Pediatrics and Psychology at the University of Miami.

G. CHRISTINA NEISON-GOENS is a doctoral candidate in the psychology department at the University of Utah.

EVANGEUNE NWOKAH is program director at the Richardson Development Center in Dallas, Texas.
The role of marital conflict as a mediator of parental drinking problems and of children's emotional regulation and adjustment is highlighted.

\section{Marital Conflict, Emotional Regulation, and the Adjustment of Children of Alcoholics}

\section{Mona El-Sheikh, E. Mark Cummings}

Understanding the effects of parental alcoholism on children is of interest to both practitioners and researchers concemed with family functioning. Relations between parental alcoholism and a wide range of childhood problems have been documented (see, for example, Roosa and others, 1988; Sher, Walitzer, Wood, and Brent, 1991; Wallace, 1987; West and Prinz, 1987). Indicating the scope of the problem, studies report that between seven million and twenty-eight million children of alcoholics (COAs) reside in the United States (Wallace, 1987), and between 16 and 24 percent of children of elementary school age are from alcoholic families (Woodside, 1988).

Until recently the COA literature was dominated by clinical observations (Black, 1979; Wilson and Orford, 1978) and popular views regarding the traumatizing effects of being reared in an alcoholic family. A main effects model regarding the impact of alcoholism on children was implicit in these treatments (Tubman, 1993), with parental recovery and other environmental variables often not considered as either ameliorating or exacerbating the negative effects of parental drinking.

The extent of adjustment problems varies, however, with many COAs not experiencing psychopathology (Bennett, Wolin, and Reiss, 1988; Clair and Genest, 1987; Moos and Billings, 1982; Sher, 1991; West and Prinz, 1987), which suggests the importance of moderating and mediating variables in relations between parental alcoholism and child outcomes (Burk and Sher, 1988;

The preparation of this manuscript was supported by a FIRST award (R29-10591) from the National Institute of Mental Health to Mona El-Sheikh.

New DireCtons For CHIID DEVEOOPMENr, no. 77 Fall 1997 Jossey-Bass Inc., Publishers 